\title{
The Attractant Bioactivity Test of Semi-Polar Fraction of the Datuan Stem Bark (Ficus vasculosa Wall. Ex Miq) against Warehouse Pest (Sitophilus oryzae L.)
}

\author{
Syaiful Bahri ${ }^{1 *}$ (D) Yuli Ambarwati $^{1}$ (D) Lina Marlina $^{2}$ (D) , Vera Fitriani ${ }^{1}$ and \\ Sutopo Hadi ${ }^{1}$ (iD \\ ${ }^{1}$ Department of Chemistry, Faculty of Mathematics and Natural Sciences, Universitas Lampung, Bandar \\ Lampung, Lampung, Indonesia. \\ ${ }^{2}$ Department of Agribusiness, Faculty of Agriculture, Universitas Lampung, Bandar Lampung, Lampung, \\ Indonesia.
}

\begin{abstract}
Bioactive isolation was performed on the stem bark of Datuan (Ficus vasculosa Wall. Ex Miq), and extraction was carried out via the maceration method using acetone as a solvent. Furthermore, an attractant bioactivity test was conducted on acetone extract, A-G fraction, and composition of the isolates. The separation and purification via column chromatography produced a D8.3.5.7 fraction in the form of needle crystal of about $50 \mathrm{mg}$, at a melting point of $136^{\circ} \mathrm{C}-138.7^{\circ} \mathrm{C}$. Thin-layer chromatography (TLC) analysis showed a single spot at an $R_{f}$ value of 0.57 ( $n$-hexane eluent: ethyl acetate 7:3), 0.36 (DCM eluent), and 0.24 ( $\mathrm{CHCl}_{3}$ eluent). The isolated compounds were identified using infrared and UV-Vis spectrophotometry, as well as mass spectrometry. The characterization of the infrared spectrum of the isolated compound showed a strong $\mathrm{OH}$ goo band at $3461 \mathrm{~cm}^{-1}$ region and the absorption band at $2936.25 \mathrm{~cm}^{-1}$ exhibited a stretch of $\mathrm{CH}$ alkanes. These two bands are supported by the vibration at 1378.47 and $1462.55 \mathrm{~cm}^{-1}$ for $\mathrm{CH}$ absorption of methyl and methylene. The absorption band in the $1622 \mathrm{~cm}^{-1}$ region showed a stretch of conjugated $\mathrm{C}=\mathrm{C}$ double bond, which is supported by absorption at 918.96 and $966.22 \mathrm{~cm}^{-1}$ as $\mathrm{C}-\mathrm{H}$ alkene. The UV-Vis spectrophotometry showed absorption at $\lambda_{\max }$ $263.97 \mathrm{~nm} A=0.483$, which was the result of electronic transition $\pi \rightarrow \pi^{*}$, and at $\lambda 331.0 \mathrm{~nm} \mathrm{A=}$ 0.274 , which was an electronic result of $n \rightarrow \pi^{*}$. Meanwhile, identification via mass spectrometry that produces isolate has a molecular weight of $414.1 \mathrm{~m} / \mathrm{e}$ with the formula $\mathrm{C}_{29} \mathrm{H}_{50} \mathrm{O}$. Therefore, the bioactivity test results on compound $D 8.3 .5 .7$ had an attractant activity of $71.67 \%$ against warehouse pests (Sitophilus oryzae L.) and an interest index of 0.63 .
\end{abstract}

Keywords: Attractant, bioactive, F. vasculosa Wall.ex Miq., S. oryzae

*Correspondence: syaiful.bahri@fmipa.unila.ac.id

(Received: April 29, 2021; accepted: September 20, 2021)

Citation: Bahri S, Ambarwati Y, Marlina L, Fitriani V, Hadi S. The Attractant Bioactivity Test of Semi-Polar Fraction of the Datuan Stem Bark (Ficus vasculosa Wall. Ex Miq) against Warehouse Pest (Sitophilus oryzae L.). J Pure Appl Microbiol. 2021;15(4):21252135. doi: 10.22207/JPAM.15.4.35

(c) The Author(s) 2021. Open Access. This article is distributed under the terms of the Creative Commons Attribution 4.0 International License which permits unrestricted use, sharing, distribution, and reproduction in any medium, provided you give appropriate credit to the original author(s) and the source, provide a link to the Creative Commons license, and indicate if changes were made. 


\section{INTRODUCTION}

Ficus is a plant genus from the family of Moraceae and order Morales, commonly found in tropical and subtropical areas worldwide. ${ }^{1,2}$ Over 500 species of this plant can be found in Indonesia and are widespread around Sumatera (102 species), Kalimantan (106 species), Papua (99 species), Sulawesi (83 species), Java (75 species), Maluku (71 species), and Nusa Tenggara (36 species). ${ }^{3}$ In general, the plant is a large woody tree that grows at a height of $30-50 \mathrm{~m}$ with a diameter of 90-110. ${ }^{1}$ The plant is usually harvested for dry and fresh consumption, especially its fruit, wood, bark, root, and leaves. Some of the parts, such as phloem fibers, are a good substitute for hemp. Moreover, the fruits of some species are edible and used as medicine. Many Ficus species are hosts to insects or warehouse pests that secretes resinous substances. Furthermore, they have some important components that are obtained for consumption or used as traditional medicine, bioactive compound, antioxidant, and pharmacological agent for human health improvement1. ${ }^{4,5}$

The sample of Ficus used in this work was obtained from Lampung, known as the Datuan plant (North Lampung). In other regions, it is known as Burut, Huru Awis, Ki Kopeng, and Ki Kuya (Sunda); its generic name is Fig (English), Ara (Malaysia), and other synonymous names. ${ }^{6}$ Studies showed numerous species of the Datuan plant are harvested and consumed due to the presence of important chemical compounds, including vitamins, minerals, carbohydrates, sugars, organic acids, phenolic compounds, flavonoids, tannins, and some other secondary metabolite compositions. ${ }^{7}$ The compounds have been pharmacologically and phytochemically studied in other studies due to their chemical constituents used medicinally. ${ }^{8}$ The plant's compositions of F. vasculosa Wall.ex Miq. (FvWM) are not only used in health but are also involved in some bioactivity tests. ${ }^{9,10}$

The FvWM contains some secondary metabolites of phenolic compounds, flavonoids, terpenoids, and steroids. ${ }^{11}$ The phenolic compounds can be classified as flavonoids and their derivatives, such as catechins, epicatechins, quercetins from $F$. sycomorus leaves, and isoflavones, including genisteinare and prunetin from F. polita, were isolated. ${ }^{12}$ Meanwhile, the bioactive compounds of the terpenoid group which are commonly isolated from the Ficus species are taraxeryl acetate, betulinic acid, and some other compounds, such as bergapten, fumaric acid, 1,4-dimethyl-7-isopropylazulene, lupeol, xanthotoxin, and more. ${ }^{12}$ Other important classes of bioactive compounds found in the genus are steroids, namely $\beta$-sitosterol isolated from $F$. polita and $\beta$-sitosterol-D-glucoside isolated from $F$. glomerata and $F$. cordata stem bark. ${ }^{13}$ The essential oil was also reported to be abundant in the $F$. ovata species i.e., (E)-menth-2-en-1-ol, $\beta$-caryophyllene, $\alpha$-pinene, 2-hexen-1-ol benzoate, limonene, simiarenol, fatty acids, aldehydes, ketones, and long-chain aliphatic hydrocarbons. ${ }^{14,15}$ The biological activities of the isolated compounds of $F$. carica species have been studied and reported that many of the secondary metabolite compounds exhibit antioxidant, anticancer, hepatoprotective, hypoglycemic, hypolipidemic, antibacterial, antipyretic, antituberculosis, irritant potential, nematicidal, antispasmodic, antiplatelet, anthelmintic, antimutagenic, as well as anti-HSV activities and oxidative stress. ${ }^{10,16}$

The present study aims to obtain bioactive compounds in the stem bark of the Datuan plant (FvWM). The bioactivity test was conducted on S. oryzae L., which is a warehouse pest in agricultural product. Extraction via maceration method using acetone as a solvent was performed to obtain the isolation compounds. Also, purification was determined through vacuum liquid chromatography (VLC) with reserved-phase gel silica Merck $60(10-40 \mu \mathrm{m})$ and gel silica Merck $60 \mathrm{GF}_{254}(63-200 \mu \mathrm{m})$ in the column. The purity of the isolated compounds was tested using thin layer chromatography (TLC), with eluents of n-hexane/ethyl acetate 7:3, dichloromethane (DCM), and $\mathrm{CHCl}_{3}$. Moreover, the melting points were determined to be $136-138.7^{\circ} \mathrm{C}$, and the molecular structures were identified using UV-Vis spectrophotometry, IR spectroscopy, and GC-MS analysis.

\section{MATERIALS AND METHODS Sample Preparation}

The stem bark of the Datuan was collected at Batunangkop Village, North Sungkai, Lampung, Sumatera, Indonesia. 


\section{Extraction and Isolation}

The sample was cleaned with water and dried at room temperature. Then, a 3-kg dried stem bark was macerated using acetone as the solvent for $6 \times 24 \mathrm{~h}$. The resultant extract was evaporated for about $24 \mathrm{~h}$ in a vacuum rotary evaporator $(60-70 \mathrm{rpm})$ at $25^{\circ} \mathrm{C}$. In addition, the concentrated extract was obtained as a crude acetone extract, and the samples were collected, weighed, and stored in a desiccator for further use.

Determination of Phytochemical Activity Contents of crude acetone extractable flavonoids

Crude acetone extract $(5 \mathrm{~mL})$ was placed in a colorimeter tube, and then $10 \%$ aqueous $\mathrm{NaOH}$ was added. Yellow-orange-red colors and white precipitation indicated the samples contained positive flavonoid.

\section{Contents of crude acetone extractable steroids}

Crude acetone extract $(5 \mathrm{~mL})\left(2 \mathrm{~mL} \mathrm{H}_{2} \mathrm{SO}_{4}\right)$ was obtained, and then $2 \mathrm{~mL}$ of anhydrate acetate acid was added. The solution was thoroughly mixed, and the resulting positive steroid content showed blue or green colors. Otherwise, when purple-black color is shown, the samples would be considered to contain terpenoid.

Contents of crude acetone extractable terpenoi Crude acetone extract $(5 \mathrm{~mL})$ was mixed with $2 \mathrm{~mL}$ of chloroform and $3 \mathrm{~mL}$ of concentrated $\mathrm{H}_{2} \mathrm{SO}_{4}$. The brown-red colors indicated the samples contain terpenoid.

\section{Biological Activity Assays}

The bioactivity of crude acetone extract samples was determined using the procedure available in the literature. ${ }^{17}$ The crude acetone and plant extract was screened for bioactivity against pests. In this assay, the pest (S. oryzae L.) was supplemented with two conditions in which the first was edible from the crude extract as attractant while the second was not edible. These treatments were seeded with 10 pests on the plates. Each sample on the plates was monitored for $24 \mathrm{~h}$ after fasting of the 10 pests for $12 \mathrm{~h}$. In addition, treatment evaluation was determined with data that can be calculated using attractive index (Al) and the percentage of attractive approach.

Equation (1) is used to determine the percentage of attractive:

$$
\% \text { Attractive }=\frac{\sum(\mathrm{a})}{\sum(\mathrm{n})} \times 100 \%
$$

Equation (2) is used to obtain attractive index (AI):

$$
\mathrm{Al}=\frac{\Sigma(\mathrm{a})-\sum(\mathrm{b})}{\sum(\mathrm{n})-\sum(\mathrm{b})}
$$

where $\Sigma(a)$ denotes the number of interested insects; $\Sigma(n)$ is the number of released insects when the extract has been added at a particular level; and $\Sigma(n)$ is the amount of Blanco insects as a control.

\section{Fractionation and Purification}

The samples of crude acetone extract were fractionated via VLC with graded eluents semi-polar using reserved-phase gel silica Merck $60(10-40 \mu \mathrm{m})$ and gel silica Merck $60 \mathrm{GF}_{254}$ (63-200 $\mu \mathrm{m})$ in the column. After obtaining the fractions from VLC, the sample fractions were dissolved in eluent mixture of ( $n$-hexane/ethyl acetate 7:3), dichloromethane (DCM), and $\mathrm{CHCl}_{3}$. Then, the sample was applied from the bottom of the gel silica $60 \mathrm{~F}_{254} 0.25 \mathrm{~mm}$ pre-coated TLC plate. Subsequently, the sample fractions were sprayed with $\mathrm{Ce}\left(\mathrm{SO}_{4}\right)_{2} \cdot 4 \mathrm{H}_{2} \mathrm{O} 1.5 \%$ and dissolved in $\mathrm{H}_{2} \mathrm{SO}_{4} 2 \mathrm{~N}$ to visualize and obtain characteristics compounds. The collected fraction was also evaluated to be similar in Rf values and color spot by TLC. Finally, the sample was stored in a desiccator for further use as a biological activity assay.

\section{Characterization}

\section{UV-Vis spectrophotometry}

The sample $(1 \mathrm{mg})$ was dissolved in 5 $\mathrm{mL} \mathrm{n}$-hexane, and the spectrum was recorded within the range of $190-380 \mathrm{~cm}^{-1}$ and $0-1.5$ absorbance. . $^{18-21}$

\section{Fourier transform infrared (FTIR) spectroscopy}

The flour sample was mixed with $\mathrm{KBr}$ and made into pellets for analysis preparation. The functional groups were determined according to IR spectrum absorption. . $^{18-21}$

\section{Gas chromatography-mass spectrometry (GC-} MS)

The sample extract was analyzed by GCMS following the described specification on GCMS/Saturn2200-CP3800 variant, equipped with capillary column DB5-MS. The chromatographic measurement conditions were set at temperature range of 230 to $300^{\circ} \mathrm{C}$, with a gradient increase of $4^{\circ} \mathrm{C} \mathrm{min}{ }^{-1}$, until final temperature was reached. 


\section{RESULTS AND DISCUSSION}

Phytochemical and Biological Activity of Crude Acetone Extract: About $4 \mathrm{~kg}$ of dried flour and approximately $30 \mathrm{~g}$ of concentrated extract of stem bark were obtained from $8 \mathrm{~kg}$ wet-stem bark of the Datuan plant (FvWM). Table 1 shows the crude acetone which can be extracted from the dried stem bark contains bioactive compounds, such as terpenoids, steroids, and flavonoids on different levels.

The results showed that an extract of the Datuan plant (FvWM) stem bark has the highest positive levels of terpenoids and steroids, and the lowest levels of flavonoids. The contents of the secondary metabolites are comparable. ${ }^{11}$ Meanwhile, the color attributes of the sample were expressed according to each content, wherein the orange-red color and white precipitation indicated positive flavonoid. To identify terpenoid and steroid, Liebermann-Burchard reagent was used, while for positive steroid content, a green color was observed using anhydrate acetate acid assay. A purple-black color of solution using $\mathrm{H}_{2} \mathrm{SO}_{4}$ assay was an indication of positive steroid, and brownred color was an indication for positive terpenoid content.

The stock concentration of the crude acetone extract was prepared by dissolving in

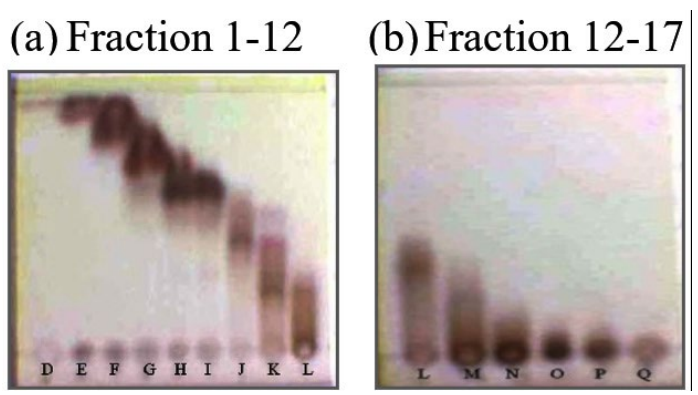

Fig. 1. Profiles of TLC chromatogram of crude aseton extract fractination; (a) Fraction 1-12: eluent $n$-hexane : ethyl acetate $80 \%$, (b) Fraction $12-17$ : eluent $n$-hexane : acetone $70 \%$.

Table 1. Levels of Phytochemical: flavonoids, terpenoids, and steroids in the stem bark of the Datuan plant species (FvWM)

\begin{tabular}{lll}
\hline Contents & Results & Levels \\
\hline Flavonoids & Orange-red colors layer and bit white precipitation & + \\
Terpenoids/steroids & $\begin{array}{l}\text { The Green color of solutions (anhydrate acetate acid test) and } \\
\text { (Lieberman- Burchard) }\end{array}$ & +++ \\
perpenoids & brown-red colors & +++ \\
\hline
\end{tabular}

Levels: + low; +++ high

acetone. The solution was further inoculated with as much as 10 pest samples. The result of the biological activity assay monitoring is presented in Table 2. Furthermore, the percentage of attractive and Al were calculated from nine different treatment times, and the bioactivity of crude acetone extract as an attractant was significantly influenced by the number of warehouse samples. In this study, nine treatments of bioactivity with different times were conducted and the results obtained vary significantly. The percentage of attractive and the Al were calculated, and the behaviors of attractant and pest samples were observed. The bioactivity was increased significantly from $0 \% ; \mathrm{Al}=0(0 \mathrm{~h}), 3 \% ; \mathrm{Al}=0.75(3$ h), $60 \% ; \mathrm{Al}=0.33(6 \mathrm{~h})$, to $100 \% ; \mathrm{Al}=1.00(9 \mathrm{~h})$ and it was effectively $100 \% ; \mathrm{Al}=1.00$ (in $21 \mathrm{~h}$ ). Also, the
Table 2. Biological Activity Assays of the crude acetone extract in the warehouse (S. oryzae L) samples

\begin{tabular}{lccccc}
\hline $\begin{array}{l}\text { Times } \\
\text { (Hours) }\end{array}$ & $\mathrm{n}$ & $\mathrm{A}$ & $\mathrm{B}$ & $\begin{array}{c}\text { Attractive } \\
\text { (\%) }\end{array}$ & $\begin{array}{c}\text { Al (Attractive } \\
\text { Index) }\end{array}$ \\
\hline 0 & 10 & 0 & 0 & 0 & 0 \\
3 & 10 & 8 & 1 & 80 & 0.75 \\
6 & 10 & 6 & 1 & 60 & 0.33 \\
9 & 10 & 10 & 0 & 100 & 1.00 \\
12 & 10 & 9 & 0 & 86.67 & 0.85 \\
15 & 10 & 8 & 2 & 80 & 0.75 \\
18 & 10 & 8 & 2 & 80 & 0.75 \\
21 & 10 & 10 & 0 & 100 & 1.00 \\
24 & 10 & 5 & 5 & 53.30 & 0.13 \\
\hline
\end{tabular}

Annotation: $\Sigma(a)$ is the number of interested insects; $\Sigma(n)$ is the number of released insects; and $\Sigma(n)$ is the amount of Blanco insects as a control. 
behavior of the pests was majorly constant from $86.67 \% ; \mathrm{Al}=0.85(12 \mathrm{~h}$ ) to $80 \% ; \mathrm{Al}=0.75$ (15 and $18 \mathrm{~h})$, a lower interaction was started $53.3 \%$; $\mathrm{Al}=$ 0.13 in $24 \mathrm{~h}$. Overall, the biological activities of the extract as an attractant were effective against the warehouse pests (S. oryzae L.).

\section{Biological Activity of Fractionated Extract Purification}

The crude acetone extract was separated using VLC. Fractionation by VLC was selected and appropriate separation solvent systems used were eluents of $n$-hexane/ethyl acetate $80 \%$ and $n$-hexane/acetone $70 \%$. The selection was performed in accordance with solvent system to identify the chemical compositions which are approximately 17 fractions, as presented in Fig. 1.

The developed TLC plates were visualized with $1.5 \%\left(\mathrm{CeSO}_{4}\right)_{2} \cdot 4 \mathrm{H}_{2} \mathrm{O}$ dissolved in $\mathrm{H}_{2} \mathrm{SO}_{4} 2 \mathrm{~N}$ reagent spray to optimize color development. The chemical composition of 17 fractions of the crude acetone extract of the stem bark was dominated by brown spots which appeared at the bottom, middle, and upper parts of the plates. 17 fractions were evaporated using a vacuum rotary evaporator, dried, and every fraction with a similar track was merged to yield 7 factions, i.e., A (1-3); B (4-6); C(7); D (8-9); E (10); F (11-12); and G (13-17).

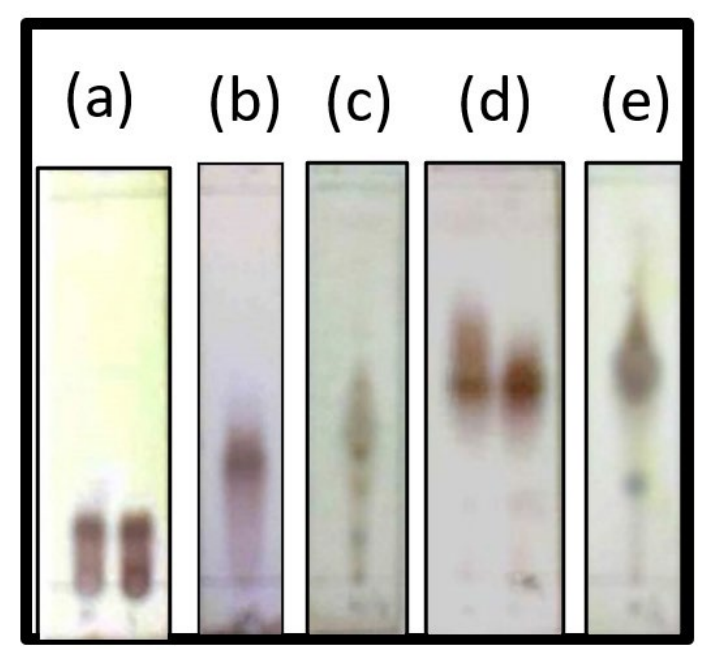

Fig. 2. Profiles of TLC chromatogram of fraction D; (a) Eluent $\mathrm{n}$-hexane : ethyl acetate $90 \%$, (b) Eluent $\mathrm{n}$-hexane ethyl acetate $85 \%$, (c) Eluent $n$-hexane : ethyl acetate $80 \%$, (d) Eluent n-hexane : ethyl acetate $75 \%$, (e) Eluent n-hexane : ethyl acetate $70 \%$
Each sample $(75 \mathrm{mg})$ of the merged fraction was dissolved in acetone to assay on the pests (S. oryzae L.). The data presented in the Table 3 shows overall attractive percentage in fractions $A, D$, and $F$ were $80 \%$, and the Als obtained were 0.77 (fraction A) and 0.75 (fractions $D$ and F). Surprisingly, at fraction $E$, negative Al value -1.00 was expressed with an attractive percentage of $33.33 \%$ which indicated that the inoculated sample (S. oryzae L.) tends to move towards control material rather than assay substance.

Separation of $A, F$, and $D$ fractions requires several stages via VLC. For $A$ fraction, after several steps of VLC and measurement by gas chromatography (GC), the chromatograms obtained were still complicated and were not resolved. Moreover, the amount of sample was insufficient for further purity and attractant activity assay. The same process was also carried out for $F$ fraction, producing the final result of F4.6 with some impurities. Nevertheless, the amount of sample was less, hence further purity actions were not taken. Therefore, D fraction was chosen for further separation and purification using TLC with an appropriate eluent solvent system (Fig. 2).

The result of TLC chromatogram profiles showed $D$ fraction contains some compounds as shown with a track spot on the chromatogram. Therefore, further separation using VLC and saturation with $\mathrm{GF}_{254}$ silica gel 60 as a reservedphase was done. $15 \mathrm{~g}$ sample of the $\mathrm{D}$ fraction was separated for re-column with appropriate separation solvent system. The VLC produced 33

Table 3. Biological Activity Assays of the fractions (A-G) in the warehouse (S. oryzae $\mathrm{L}$ ) samples

\begin{tabular}{lccccc}
\hline Fractions & N & A & B & $\begin{array}{c}\text { Attractive } \\
(\%)\end{array}$ & $\begin{array}{c}\text { Al (Attractive } \\
\text { Index) }\end{array}$ \\
\hline A & 15 & 12 & 2 & 80 & 0.77 \\
B & 15 & 9 & 1 & 60 & 0.57 \\
C & 15 & 9 & 3 & 60 & 0.50 \\
D & 15 & 12 & 3 & 80 & 0.75 \\
E & 15 & 5 & 10 & 33.33 & -1.00 \\
F & 15 & 12 & 3 & 80 & 0.75 \\
G & 15 & 5 & 5 & 33.33 & 0 \\
\hline
\end{tabular}

Annotation: $\Sigma(a)$ is the number of interested insects; $\Sigma(n)$ is the number of released insects; and $\Sigma(n)$ is the amount of Blanco insects as a control. 
fractions, each containing $10 \mathrm{~mL}$. Furthermore, TLC was carried out to represent the whole samples, and the result is shown in Fig. $3 a$.

The same TLC tracks were merged to produce D1, D2, D3, D4, D5, D6, D7, D8 (8-11), D9 (12-13), D10 (14-18), D11 (19-24),D(25-29), and D13 (30-33) fractions. Among all the fractions, D8 was selected for re-column using eluent variations of $n$-hexane and ethyl acetate. The result of the re-column of D8 were 20 fractions, then TLC was carried out on these fractions using eluent of $n$-hexane/ethyl acetate $87.5 \%$, and the result is shown in Fig. $3 \mathrm{~b}$. The same tracks of TLC were subsequently combined and 7 fraction combinations were obtained, i.e., D8.1 (1-4); D8.2 (5-6); D8.3 (7-16); D8.4; D8.5; D8.6; and D.7.

D8.3 was selected for re-column, and 16 fractions were obtained. TLC was carried out on the samples of the 6 fractions in order to visualize the TLC profiles of each, and 11 combinations were obtained, namely D8.3.1; D8.3.2; D8.3.3; D8.3.4; D8.3.5 (5-10); D8.3.6; D8.3.7; D8.3.8;

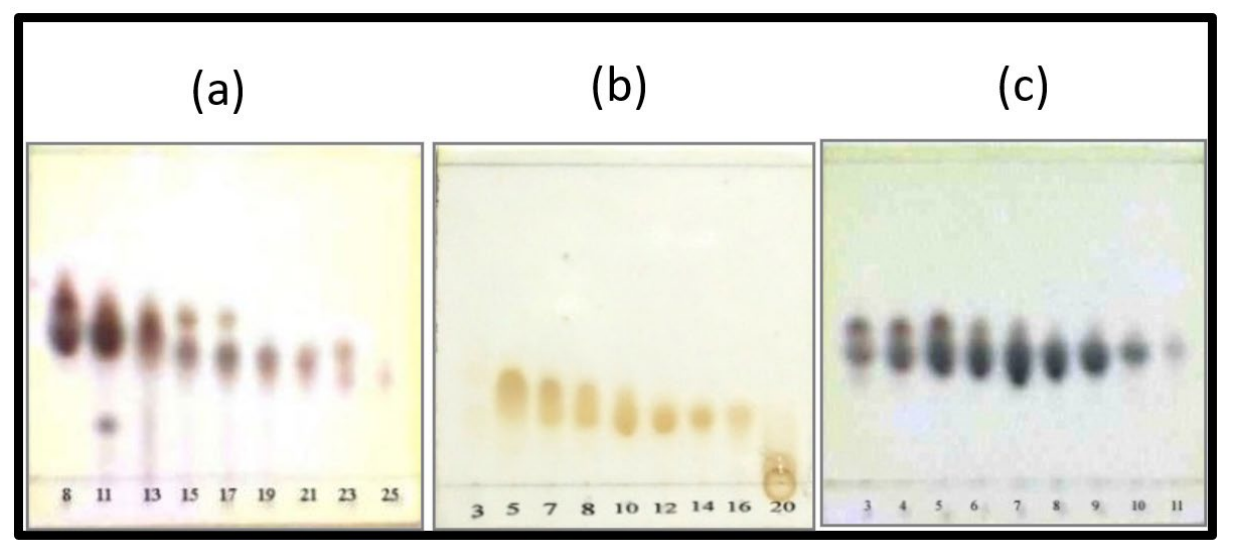

Fig. 3. Profiles of TLC chromatogram of recolumn fractions; (a) Fraction D : eluent $n$-hexane : ethyl acetate $75 \%$, (b) Fraction D8 : eluent n-hexane : ethyl acetate 87,5\%, (c) Fraction D8.3 : eluent n-hexane : ethyl acetate $80 \%$.

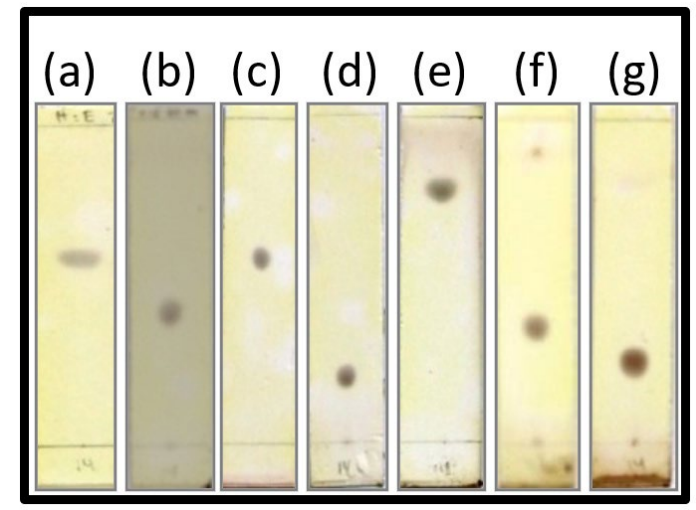

Fig. 4. Profiles of TLC chromatogram of fraction D8.3.5.7; (a) Eluent $n$-hexane : ethyl acetate $70 \%(\mathrm{Rf}=0.57)$, (b) Eluent $n$-hexane : ethyl acetate $80 \%\left(R_{f}=0.42\right)$, (c) Eluent $\mathrm{CCl}_{4}$ : ethyl acetate $70 \%\left(\mathrm{R}_{\mathrm{f}}=0.57\right)$, (d) Eluent $\mathrm{n}$-hexane : ethyl acetate $90 \%\left(R_{f}=0.21\right)$, (e) Eluent $n$-hexane : ethyl acetate $60 \%\left(R_{f}=0.79\right)$, (f) Eluent Dichloromethane (DCM) $100 \%\left(R_{f}=0.36\right)$, (g) Eluent Chloroform $\left(\mathrm{CHCl}_{3}\right)$ $100 \%(\mathrm{Rf}=0.24)$.
D8.3.9; D8.3.10; and D8.3.11. The profiles of the TLC chromatogram of fraction D8.3 are presented in Fig. 3c.

A yellow crystal with some impurities were formed for D8.3.5. Also, the crystal containing D8.3.5 fraction was purified and combined for recolumn using eluent variations of $n$-hexane and ethyl acetate. Furthermore, the re-column results were collected for every $0.5 \mathrm{~mL}$ and 36 fractions were obtained. From the 7-24 which were merged as D8.3.5.7 fraction, colorless needle-shaped crystal was formed. The melting points of the crystal are in the range of $136^{\circ} \mathrm{C}-138.7^{\circ} \mathrm{C}$. This melting point range implicated that the crystal is not yet pure. Subsequently, the sample containing D8.3.5.7 was further separated with TLC using various eluent system and is presented in Fig. 4 where one final purple spot, and approximately $\pm 50 \mathrm{mg}$ of D8.3.5.7 crystal fraction were obtained. The test carried out with Liebermann-Burchard 
reagent to identify the phytochemical compound of the crystal showed the sample exhibited purpleblack color, meaning the steroid was present in the crystal.

To investigate the biological activity of D8.3.5.7 crystal fraction, the sample was tested as an attractant and as much as 15 samples of $S$. oryzae L. were inoculated. Data in Table 4 shows the pests tend to move towards the material

Table 4. Biological Activity Assays of the fractions D8.3.5.7 in the warehouse (S. oryzae L) samples

\begin{tabular}{lccccc}
\hline $\begin{array}{l}\text { Time } \\
\text { (Hour) }\end{array}$ & $\mathrm{n}$ & $\mathrm{A}$ & $\mathrm{B}$ & $\begin{array}{c}\text { Attractive } \\
\%\end{array}$ & $\begin{array}{c}\text { Al (Attractive } \\
\text { Index) }\end{array}$ \\
\hline 0 & 15 & 0 & 0 & 0 & 0 \\
3 & 15 & 10 & 4 & 66.67 & 0.55 \\
6 & 15 & 12 & 3 & 80 & 0.75 \\
9 & 15 & 11 & 3 & 73.33 & 0.67 \\
12 & 15 & 11 & 4 & 73.33 & 0.64 \\
15 & 15 & 12 & 3 & 80 & 0.75 \\
18 & 15 & 12 & 2 & 80 & 0.77 \\
21 & 15 & 10 & 5 & 66.67 & 0.50 \\
24 & 15 & 8 & 5 & 53.33 & 0.40 \\
\hline
\end{tabular}

Annotation: $\Sigma(a)$ is the number of interested insects; $\Sigma(n)$ is the number of released insects; and $\Sigma(n)$ is the amount of blank insects as a control.

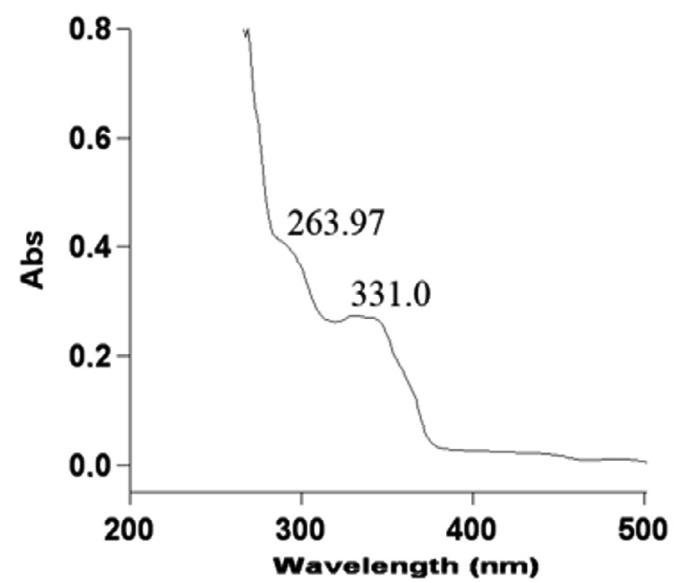

Fig. 5. UV-Vis spectrum of isolated compounds of D8.3.5.7 fraction. tested as attractant. This activity declined after $21 \mathrm{~h}$, although it was not significant. Based on this investigation, it can be stated that the isolated compound of D8.3.5.7 fraction of the Datuan plant (FvWM) bark is active and effective as an attractant against pests, where the attractive percentage average was $71.67 \%$ and $\mathrm{Al}$ was $0.63 \%$.

Some works have reported the biological activity of Ficus sp. ${ }^{22-24}$ and showed some variations in the results obtained. The volatile compositions of leaf extracts of $F$. hispida has been investigated on the specificity of fig wasp attractiveness, however the leaf extracts of $F$. hispida did not show significant activity in the wasp attraction. ${ }^{22}$ The work on $F$. ingens has indicated that it attracts its specific wasp pollinator using its odours formed. ${ }^{23}$ In this work has also been shown that most of the fig species have only one legitimate wasp pollinator species, it is to be expected that different fig species produce different compounds. ${ }^{23}$ Furthermore, results showed that the chemical analysis of vaporous from F. sycomorus leaves allowed identification the bioactive phytochemicals from $F$. sycomorus leaves were reported to be more toxic as the fumigant toxicity tests than the contact phase to the tested insects. ${ }^{24}$ Compared to those reported works, the compound isolated in this work was indicated to show a good attractant activity although the activity test carried out was different.

\section{Structural Properties}

UV-Vis spectrophotometry

The UV-Vis spectrum of the isolated compound D8.3.5.7 fraction has maximum absorptions ( $\lambda_{\max }^{n-\text { Hexane }}$ ) of 263.97 and $331.0 \mathrm{~nm}$ with absorbance values $(A)$ of 0.483 and 0.274 , respectively. The $\lambda_{\max } 263.97 \mathrm{~nm}$ with $A=0.483$ was a result of electronic transition $\pi \rightarrow \pi^{*}$ and at $\lambda_{\text {max }}$ $331.0 \mathrm{~nm}$ with $\mathrm{A}=0.274$ was electronic transition due to $n \rightarrow \pi^{*}$. These absorbance values were

Table 5. Molar absorptivity $(\varepsilon)$ values of the isolated compound of D8.3.5.7 fraction using the Lambert-Beer equation

\begin{tabular}{lcc}
\hline $\begin{array}{l}\text { Wavelength } \\
(\mathrm{nm})\end{array}$ & $\begin{array}{c}\text { Absorbance } \\
(\mathrm{A})\end{array}$ & $\begin{array}{c}\text { Molar absorptivity } \\
(\varepsilon)\end{array}$ \\
\hline 263.97 & 0.483 & 714.497 \\
331.00 & 0.274 & 405.325 \\
\hline
\end{tabular}


Table 6. FTIR absorption areas of the isolated compound of D8.3.5.7 fraction

\begin{tabular}{lc}
\hline $\begin{array}{l}\text { Absorption } \\
\text { areas }\left(\mathrm{cm}^{-1}\right)\end{array}$ & $\begin{array}{c}\text { Vibrations of functional } \\
\text { groups }\end{array}$ \\
\hline 918.96 & C-H bending (alkene) \\
966.22 & C-H bending (alkene) \\
1039.97 & C-O stretching (Carbonyl) \\
1378.47 & C-H bending (Methyl) \\
1462.55 & C-H bending (Methylen) \\
1622.39 & C=C stretching (Non-conjugated) \\
2936.25 & C-H stretching (Alkane) \\
3461.62 & O-H strecthing (Alcohol) \\
\hline
\end{tabular}

used to calculate molar absorptivity $(\varepsilon)$ with the Beer-Lambert equation using sample with a mass of $0.0014 \mathrm{~g}$, solvent volume $5 \mathrm{~mL}$-hexane and molecular weight of $414 \mathrm{~g} / \mathrm{mol}$ (based on the MS result as described in 3.2.3). The data of calculated $\varepsilon$ are presented in Table 5.

Fourier Transform Infrared (FTIR) Spectroscopy

The FTIR spectrum of the isolated compounds D8.3.5.7 fraction is presented in Fig. 7. The sample showed a broadband of $3461.62 \mathrm{~cm}^{-1}$ corresponding to the symmetric and asymmetric stretching of hydrogen-bonded $\mathrm{O}-\mathrm{H}$ groups. The bands between 1378.47 and $1462.55 \mathrm{~cm}^{-1}$ were

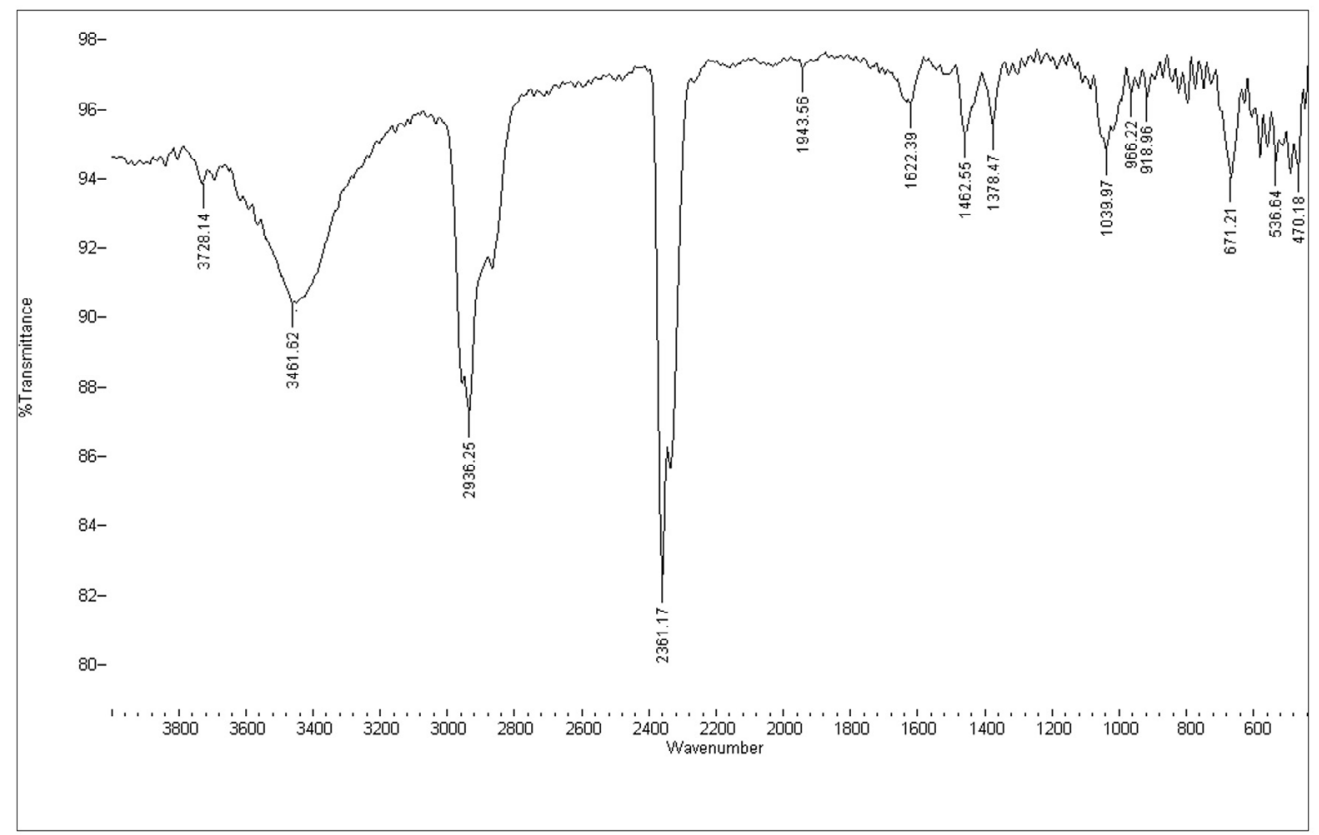

Fig. 6. FTIR spectrum of isolated compounds of D8.3.5.7 fraction.

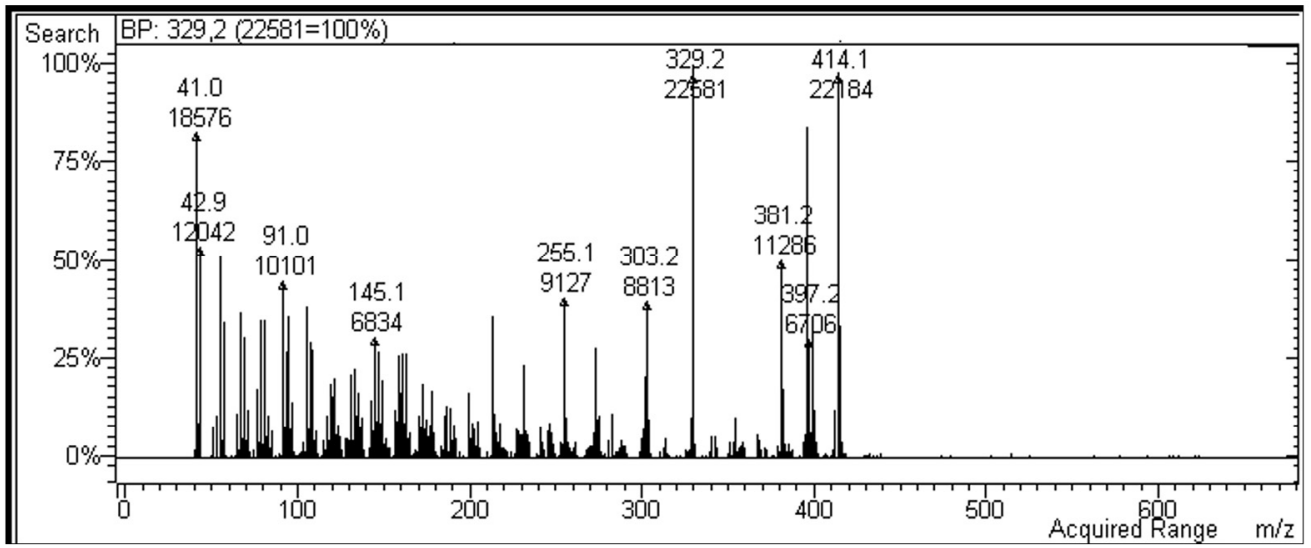

Fig. 7. Mass spectra of isolated compounds of fraction D8.3.5.7. 
<smiles>CCC(CCC(C)C1CCC2C3CC=C4CC(O)CCC4(C)C3CCC12C)C(C)C</smiles>

Fig. 8. The proposed structure of $(3 \beta, 24 S)$-stigmast-5en-3-ol with synonym as $\beta$-sitosterol.

indicated by $\mathrm{C}-\mathrm{H}$ stretching vibration, which were attributed to the $\mathrm{CH}_{3}$ and $\mathrm{CH}_{2}$ groups, respectively. The $\mathrm{C}-\mathrm{O}$ stretching vibrations were observed at $1039.97 \mathrm{~cm}^{-1}$. Besides, the peak of $1622 \mathrm{~cm}^{-1}$ was ascribed by $\mathrm{C}=\mathrm{C}$ non-conjugated stretching vibration, which corresponds with absorption of alkene bonded at 918.96 and $966.22 \mathrm{~cm}^{-1}$. This isolated compound of the Datuan plant has no absorption at the aromatic areas at about $3000 \mathrm{~cm}^{-1}$, and also overtone areas at 1604, 1801,1870, and $1941 \mathrm{~cm}^{-1}$, which showed the isolated compound of D8.3.5.7 fraction has no aromatic chain compounds. ${ }^{18-21}$ This leads to the absorption spectrum of UV-Vis spectrophotometry measurement which is the absorption under visible light. For details, the bonding properties of FTIR are presented in Table 6.

Gas chromatography-mass spectrometry (GCMS)

Fig. 8 presents the typical MS fingerprint of the isolated compound of fraction D8.3.5.7 which was extracted from the stem bark of the Datuan plant (FVWM). The mass spectrum of the sample is mainly characterized by abundant ion peak $\mathrm{M}^{+}=414.1(100 \%)$ and $\mathrm{m} / \mathrm{e}=392.2(100 \%)$ as the base peak. The ion fragment peaks appeared at $\mathrm{m} / \mathrm{e}=397.2 ; \mathrm{m} / \mathrm{e}=381.2 ; \mathrm{m} / \mathrm{e}=303.3 ; \mathrm{m} / \mathrm{e}=$ $255.1 ; \mathrm{m} / \mathrm{e}=145 ; \mathrm{m} / \mathrm{e} 91.0 ; \mathrm{m} / \mathrm{e}=42.9 ;$ and $\mathrm{m} / \mathrm{e}$ $=41.0$. In this case, the retention time (Rt) was obtained as 22.208 min via GC-MS. Based on the FTIR spectra and functional group vibration, absorption of UV-Vis spectrum, and also mass spectra fingerprint of the sample, it was shown that the isolated compound of D8.3.5,7 sample has a chemical formula of $\mathrm{C}_{29} \mathrm{H}_{50} \mathrm{O}$.
To show the double bond and circumference structure of the compound resulting from the isolation, a double bond equivalent (DBE) calculation was performed as follows:

$\mathrm{DBE}=$ Amount of $\mathrm{C}$ atoms $-\frac{\text { Amount of } \mathrm{H} \text { atoms }}{2} 1$
$\mathrm{DBE}=29-25+1=5$

\section{Structural Elucidations}

The compound from D8.3.5.7 presented in Fig. 9 was isolated from the crude acetone extract of the Datuan plant (FvWM) stem bark. The MS spectrum of this compound showed molecular ion peak at $\mathrm{M}^{+}=414.1$ (100\%). According to nitrogen rule, a compound having an even molecular weight contains $\mathrm{C}, \mathrm{H}$ and $\mathrm{O}$ atoms or when the compound contains nitrogen atoms, then the number of nitrogen atoms needs to be even. ${ }^{25}$ Therefore, it is assumed that this compound does not contain nitrogen because based on the infrared spectrum, there is no $\mathrm{N}-\mathrm{H}$ stretching vibration absorption in the 3300-3400 $\mathrm{cm}^{-1}$ region or C-N stretching in the $1020-1250 \mathrm{~cm}^{-1}$ region. Based on this analyses and the molecular weight of the compound with formula of $\mathrm{C}_{29} \mathrm{H}_{50} \mathrm{O}$, it was suggested that the compound is a steroid. Therefore, the proposed structure of isolate from D8.3.5.7 fraction is $(3 \beta, 24 \mathrm{~S})$-stigmast-5-en-3-ol and it is also known as $\beta$-sitosterol. ${ }^{12}$

\section{CONCLUSION}

The isolated compound from D8.3.5.7 fraction was obtained in the form of a colorless needle-shaped crystal with a melting point of $136^{\circ} \mathrm{C}-138.7^{\circ} \mathrm{C}$, and mass of approximately \pm 50 mg. Also, UV-Vis spectrophotometry, FTIR, and GC-MS showed the isolated compound is $(3 \beta$, 24S)-stigmast-5-en-3-ol which is synonymous with $\beta$-sitosterol, and its molecular formula is $\mathrm{C}_{29} \mathrm{H}_{50} \mathrm{O}$, while its molecular weight is $\mathrm{M}+=141.1$ $\mathrm{g} / \mathrm{mol}$. Moreover, it is considered as a steroid compound. The bioactivity assay result of the samples showed the Datuan plant is effective as an attractant against pests (S. oryzae L.), with attractive percentage average and Al were $71.67 \%$ and 0.63 , respectively.

\section{ACKNOWLEDGMENTS}

Our gratitude to Research and Community Services, Universitas Lampung that have provided 
funding for Basic Research Grants (Penelitian Dasar). We also thank Enago (www.enago.com) for English review and proofreading of this paper.

\section{CONFLICT OF INTEREST}

The authors declare that there is no conflict of interest.

\section{AUTHORS' CONTRIBUTION}

All authors have made substantial, direct and intellectual contribution to the work and approved it for publication.

\section{FUNDING}

This study was funded by Universitas Lampung, Basic Research Grants (Penelitian Dasar) 2020.

\section{DATA AVAILABILITY}

All datasets generated or analyzed during this study are included in the manuscript.

\section{ETHICS STATEMENT}

This article does not contain any studies with human participants or animals performed by any of the authors.

\section{REFERENCES}

1. Berg CC, Classification and distribution of Ficus. Experientia. 1989;45:605-611. doi: 10.1007/ BF01975677

2. Van Noort S, Gardiner AJ, Tolley KA. New records of Ficus (Moraceae) species emphasize the conservation significance of inselbergs in Mozambique. South Afr J Bot. 2007;73(4):642-649. doi: 10.1016/j. sajb.2007.04.063

3. Yusuf R. Ecological and Diversity distribution of Ficus spp.. Berkala Penel Hayati, Special Ed. 2011;5(A):83-91. (in Indonesian)

4. Shi $Y-X, X u Y-K, H u ~ H-B, N a Z$, Wang W-H. Preliminary assessment of antioxidant activity of young edible leaves of seven Ficus species in the ethnic diet in Xishuangbanna, Southwest China. Food Chem. 2011;128(4):889-894. doi: 10.1016/j. foodchem.2011.03.113

5. Li JJ, Mo L, Song JL. Improvement effect of Ficus vasculosa ethanol extract on D-galactose-Induced mice aging. SAGE Nat Prod Comm. 2019;14(12):1-7. doi: $10.1177 / 1934578 \times 19896676$

6. Hendrayana $Y$, Widodo $P$, Kusmana $C$, Widhiono I. Diversity and distribution of figs (Ficus spp.) across altitudes in Gunung Tilu, Kuningan, West Java, Indonesia. Biodiversitas. 2019;20(6):1568-1574. doi: $10.13057 /$ biodiv/d200612

7. Slatnar A, Klancar U, Stampar F, Veberic R. Effect of drying of Figs (Ficus carica L.) on the contents of sugars, organic acids, and phenolic compounds. J Agri Food Chem. 2011;59(21):11696-11702. doi: 10.1021/ jf202707y

8. Chawla A, Kaur R, Sharma AK. Ficus carica Linn.: A review on its pharmacognostic, phytochemical and pharmacological aspects. Int J Pharm Phytopharm Res. 2012;1(4):215-232.

9. Sandabe UK, Onyeyili PA, Chibuzo GA. Phytochemical screening and effect of aqueous extract of Ficus sycomorus $\mathrm{L}$. (Moraceae) stembark on muscular activity in laboratory animals. J Ethnopharm. 2006;103(3):481483. doi: 10.1016/j.jep.2005.08.025

10. Mawa S, Husain K, Jantan I. Ficus carica L. (Moraceae): phytochemistry, traditional uses and biological activities. Ev Based Complement Alternat Med. 2013;2013:974256. doi: 10.1155/2013/974256

11. Chen L-W, Cheng M-J, Peng C-F, Chen I-S. Secondary metabolites and antimycobacterial activities from the roots of Ficus nervosa. Chem Biodivers. 2010;7(7):18141821. doi: 10.1002/cbdv.200900227

12. Kuete V, Kamga J, Sandjo LP, et al. Antimicrobial activities of the methanol extract, fractions and compounds from Ficus polita Vahl. (Moraceae). BMC Complement Alterna Med. 2011;11:6. doi: 10.1186/1472-6882-11-6

13. Wu PL, Rao KV, Su CH, Kuoh CS, Wu TS. Phenanthroindolizidine alkaloids and their cytotoxicity from the leaves of Ficus septica. Heterocycles. 2002;57(12):2401-2408. doi: 10.3987/COM-02-9615

14. Chiang YM, Chang JY, Kuo CC, Chang CY, Kuo YH. Cytotoxic triterpenes from the aerial roots of Ficus microcarpa. Phytochemistry. 2005;66(4):495-501. doi: 10.1016/j.phytochem.2004.12.026

15. Lansky EP, Paavilainen HM, Pawlus AD, Newman RB. Ficus spp. (fig): Ethnobotany and potential as anticancer and anti-inflammatory agents. $J$ Ethnopharm. 2008;119(2):195-213. doi: 10.1016/j. jep.2008.06.025

16. Channabasavaraj KP, Badami S, Bhojraj S. Hepatoprotective and antioxidant activity of methanol extract of Ficus glomerate. J Nat Med. 2008;62(3):379383. doi: 10.1007/s11418-008-0245-0

17. Alonso-Amelot ME, Avila-Núñez JE. Comparison of seven methods for stored cereal losses to insects for their application in rural conditions. J Stored Prod Res. 2011;47(2):82-87. doi: 10.1016/j.jspr.2011.01.001

18. Hadi S, Noviany. The Isolation of Hopeaphenol, a Tetramer Stilbene, from Shorea ovalis Blume. Adv Nat App/ Sci. 2009;3(1):107-112.

19. Suhartati T, Yandri, Suwandi JF, Hadi S. In vitro and in vivo antiplasmodial activity of oxyresveratrol and artonine isolated from two Artocarpus plants in Indonesia. Orient J Chem. 2010;26(3):825-830.

20. Noviany $\mathrm{N}$, Nurhidayat $\mathrm{A}, \mathrm{Hadi}$ S, et al. Sesbagrandiflorain $A$ and $B$ : isolation of two new 2-arylbenzofurans from the stem bark of Sesbania grandiflora. Nat Prod Res. 2018;32:2558-2564. doi: 10.1080/14786419.2018.1425858

21. Noviany N, Sialdian D, Setiawan A, Irawan B, Azmi MN, Hadi S. Bioassay-Guided Separation Approach for Characterization of New Antibacterial Fractions from the Stem Roots Extracts of Archidendron jiringa. 
J Turk Chem Sect A. 2021;8(2):393-404. doi: 10.18596/ jotcsa.831054

22. Song $Q$, Yang $D$, Zhang $G$, Yang $C$. Volatiles from Ficus hispida and Their Attractiveness to Fig Wasps. J Chem Eco. 2001;27(10):1929-1942. doi: 10.1023/a:1012226400586

23. Barker NP. Evidence of a volatile attractant in Ficus ingens (Moraceae). Bothalia. 1984;15(3/4):a1854. doi: 10.4102/abc.v15i3/4.1854

24. Romeh AA. Phytochemicals from Ficus sycomorus L. leaves act as insecticides and acaricide. Afr J Agri Res. 2013;8(27):3571-3579. doi: 10.5897/AJAR2013.7243

25. Pellegrin V. Molecular formulas of organic compounds: the nitrogen rule and degree of unsaturation. $J$ Chem Edu. 1983;60(8):626. doi: 10.1021/ed060p626 